\title{
Supporting plate edge radius and internal hole diameter relation effect on the springback in incremental forming, part B
}

\author{
Khalil Ibrahim Abass* \\ AL-Mustansiriya University, Engineering College, Mechanical Engineering Department, Baghdad, Iraq
}

\begin{abstract}
Incremental Forming, IF technology is a method for producing complex 3D-dimensional sheet profiles. Compared to conventional forming process, IF has some advantages, such as the punch-die set product deformation is not necessary, lower tools cost, shorter time prototype production, flexibility. The accuracy of the incremental forming products is still lower than those produced by the conventional forming process. One of the main parts of the IF tools-set is the supporting tools. The product profile accuracy limits the simplicity or complexity of the supporting tools. When the product profile does not contain a horizontal surface, the simple supporting tool can be used. If the product profile is more complex, the supporting tools should include more details. The present work introduces the effect of supporting plate radiuses in SPIF, Single Point Incremental Forming process. The supporting plate is used to investigate the effect of springback during the forming process. Aluminum sheet metals (A1025) are used for manufacturing the products. The study objective is to understand the springback behavior, which is affected by supporting tools. The strain distributions of the final deformed product section at each step size have been analyzed and evaluated in detail.
\end{abstract}

\section{Introduction}

Incremental Forming, IF process is a quite recent technology for manufacturing applications and has some drawbacks: a) the product precision is limited (-1 mm thickness); b) the lubrication is essential, due to the direct contact (forming tool-blank), heat is generated; c) the surface finish is reduced; and d) the mass production is low [1].

The limitations of IF processes are that the dimensional precision of the deformed products are affected by the springback effect [2].

The IF forming process applications are appreciated in terms of dimensional accuracy to lower than $1 \mathrm{~mm}$ tolerance (or even less than $\pm 0.5 \mathrm{~mm}$ ) [3]. The tolerances of the symmetrical profiles are $\pm 1.5 \mathrm{~mm}$ and $\pm 2.0 \mathrm{~mm}$ for asymmetric profiles [4].

The springback affects the geometrical accuracy of the final product. It is the geometric variation completed by a product at the end step of the forming process, when the product has been unrestricted from the forming tool forces. Also, the springback in IF appears near

*Corresponding author: k.i.abass@uomustansiriyah.edu.iq 
the deformed region, exactly after the forming tool has deformed it. The investigators studied this matter and they recommended several proposals to develop the geometrical accuracy of IF products:

- use backing plate for supporting the blank edges [3, 5];

- reduce the springback by selecting the forming tool radius and step size as small as possible [6-7];

- minimize the springback effect by using multi pass during the forming trajectory [5], as the springback increases when the number of stages increases as indicated by [8];

- reduce the springback by adjusting the dimensional precision and correcting the toolpath "in-process" [9], or "out-process"; the divergences of the deformed product from the CADmodel were measured $[3,10]$;

- the springback deviation from the finite element analysis, FEA and the CAD-model is defined and redefined to improve the forming tool strategy [10];

- new algorithm based on the toolpath is presented by [11];

- various models are proposed to solve accuracy problems by using flexible systems with high complexity [12];

- use local heat by laser assisted or heating the total blank before the forming process to improve formability during IF process [13-14].

In the present study, using the supporting plate is employed to find the relation effect between the springback defect and the supporting profile during the forming process. The study targets to determine the strain distribution for the deformed product section at each step size. Furthermore, influences leading to failure of the final product were discussed and analyzed. Aluminum (A1025) alloy sheets to deform a product with a frustum cone geometry using a supporting plate (with 1-20 mm radius) are used.

\section{FE simulation model development}

The FE simulation model was undertaken to represent the metal forming process. The input stage involves physical SPIF model geometry, material properties and boundary conditions. The processing stage takes into account the analysis of FEM and evaluated shape, for the failure product or success. The output stage includes the final product for calculation and conclusions [15].

To develop the FE model, the effect of the supporting plate edge radius was studied with constant values (materials and dimension) of fixture (die and blank holder) and blank, as shown in Tables 1 and 2.

Symmetric components to model blanks are used, that are rotated about an axis symmetrically. The 2D analysis of the sector of the deformed blank is carried out in order to evaluate the complete shape of the product. An Aluminum AA1050 material as a workpiece was used, and the mechanical properties are shown in Table 1.

The PLANE42-2D element is used to represent the rigid set and the V15C0106-2D element to represent the flexible set is used. The pair Point-to-Surface contact elements CONTAC169 and CONTAC171-2D were used to represent the contact conditions, like a Rigid-to-Flexible contact between the tool set and the blank respectively. The contact surfaces, a real constant set were used for each interface, and are represented as:

- Rigid (forming tool) $\backslash$ Flexible (workpiece) contact;

- Rigid (blank holder) $\backslash$ Rigid (supporting plate) contact;

- Flexible (workpiece) $\backslash$ Rigid (supporting plate) contact.

The boundary conditions include loading, displacement, friction coefficient and direct and indirect contact, as represented in [15]. A convergence criterion, non-linear analysis, and specified incremental boundary conditions are applied. The tolerance of convergence was created depending on the force residual minimization. 
Table 1. Material properties of the blank, Al (AA1050).

\begin{tabular}{cccccc}
\hline Young's modulus, E & Poisson's ratio, $v$ & Density, $\rho$ & Tangent modules, E $\tau$ & \multicolumn{1}{c}{ Tensile Strength } \\
\hline $75 \mathrm{GPa}$ & 0.3 & $2700 \mathrm{~g} / \mathrm{m}^{3}$ & $0.5 \mathrm{GPa}$ & $105-145 \mathrm{MPa}$ \\
\hline & & & & \multicolumn{2}{c}{ Table 2. Initial SPIF data. } \\
\hline & & Variable & Value \\
\hline
\end{tabular}

Fig. 1. SPIF process components.

\section{Results and discussion}

The approach covers two series (Figure 2-(1)), and both have the same boundary conditions: a. constant internal supported plate radius, $80 \mathrm{~mm}$ with varying edge radius values, $\mathrm{R}=2.5-15 \mathrm{~mm}$; b. constant supporting space, $\mathrm{Ss}, 5 \mathrm{~mm}$ and eight values of the supported plate edge radius $(\mathrm{R}=2.5$ $\mathrm{mm}$ variance for each test), and for predicting the failure statuses $1 \mathrm{~mm}$ edge radius is used.

Successive stages using the supporting plate edge radius $(\mathrm{R}=15 \mathrm{~mm})$ to produce the SPIF product profile are shown in Figure 2-(2). The forming tool path influences significantly the stress distribution values, also these values increase with the deforming depth. The highest appears to be a good indication to evaluate the failure of success of the deformed product.

SPIF simulation model of the frustum cone profile with $47 \mathrm{~mm}$ depth is shown in the Figure 2-(2). The springback is increasing with depth; the stress distributions along the deformed blank section are increasing as well. The blank material tends to wrap around the tool profile which leads to increasing the friction region that causes fracture. The highest values of the stresses are under and near the tool position during its progresses in deforming depth. The space region does not suffer high plastic stress during deformation steps, thus the thickness is near the original.

Series a, internal supporting plate radius is constant $80 \mathrm{~mm}$; spaces range between 2.5 $\mathrm{mm}$ until $15 \mathrm{~mm}$ with increasing level $2.5 \mathrm{~mm}$, respectively with $\mathrm{R} \mathrm{mm}$. At $\mathrm{R}=2.5 \mathrm{~mm}$, failure occurred at depth $9.2 \mathrm{~mm}$ because during the forming proceed the gab became less than sheet thickness. Also, the largest surface area and the largest deforming region (Figure 3) are and effect of the forming tool contact.

When increasing $\mathrm{R}$, the metal surface area under the deforming tool is decreasing, and this condition leads to elastic environment remaining under the blank metal (within space); the bending and friction effects along the edge of the supporting plate are with low rate and late.

Series $\mathrm{b}$, supporting plate spaces starts at $10 \mathrm{~mm}$ from the forming tool center, with $\mathrm{R}$ ranging between $2.5-20 \mathrm{~mm}$; also $\mathrm{R}=1 \mathrm{~mm}$ is used to test the lowest radius of the supporting edge. In other words, the testing plan in the series $\mathrm{b}$ considers constant space with variant radius of the supporting plate edge. Constant supporting space means constant deforming contact distance, which depends on the forming tool path (Figure 4).

The smallest radius $\mathrm{R}=1 \mathrm{~mm}$ is working as a clamp to force the metal against the stretching forces resulting from the forming tool movement. Increasing the edge radius allows the metal to bend and to stretch depending on the friction conditions with a strain rate. Increasing the edge radius works as a deforming controller and orients the metal blank forming. 

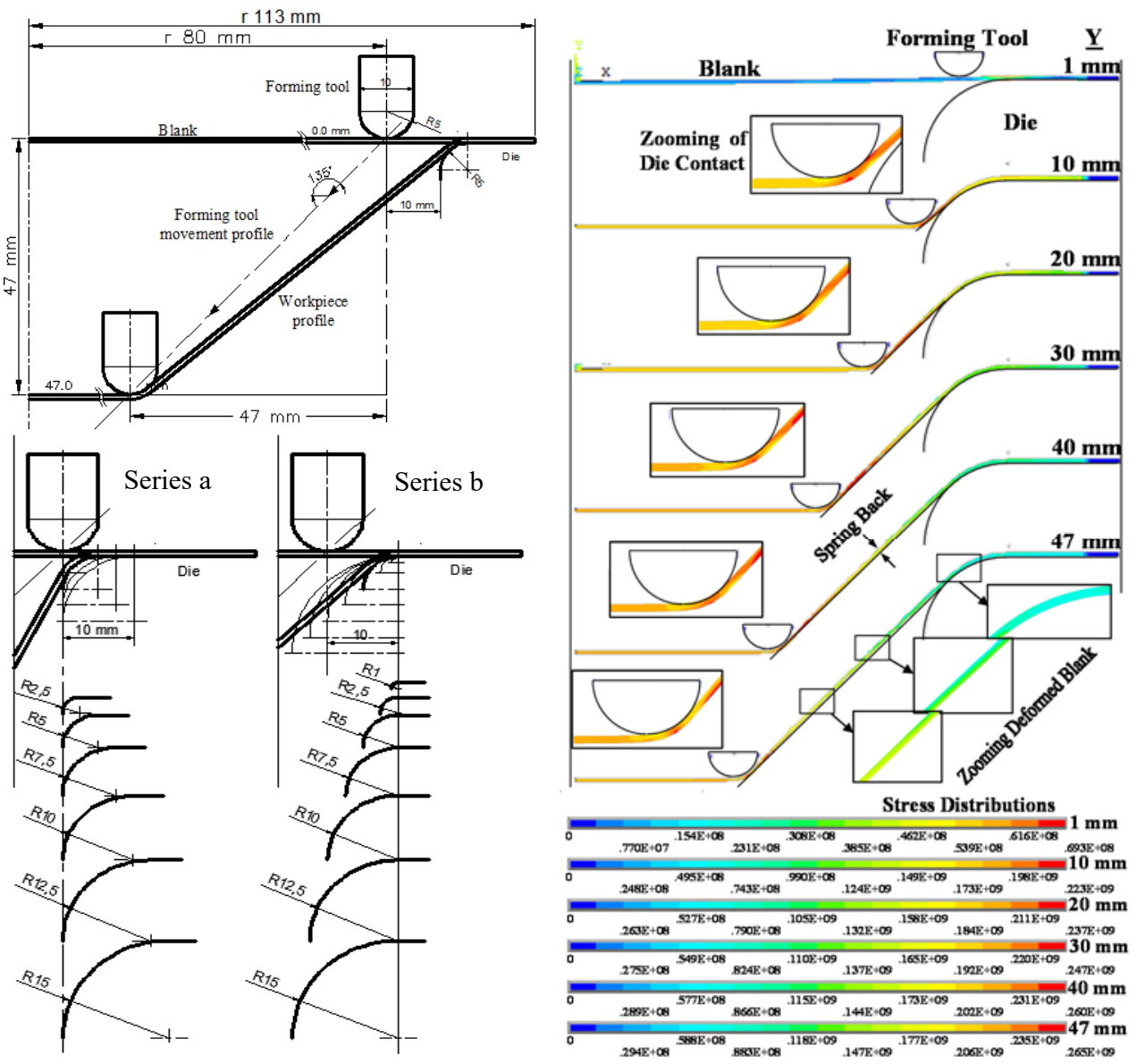

Fig. 2. Methodology details of supporting plate edge radius and internal hole diameter effect.

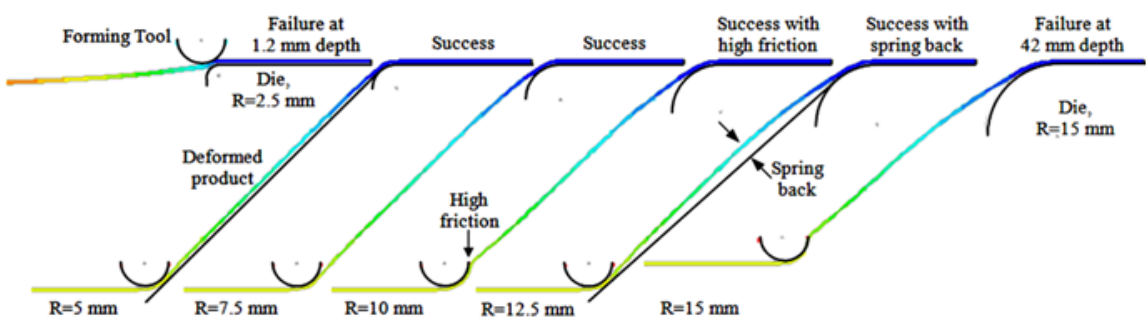

Fig. 3. SPIF process products, series a.

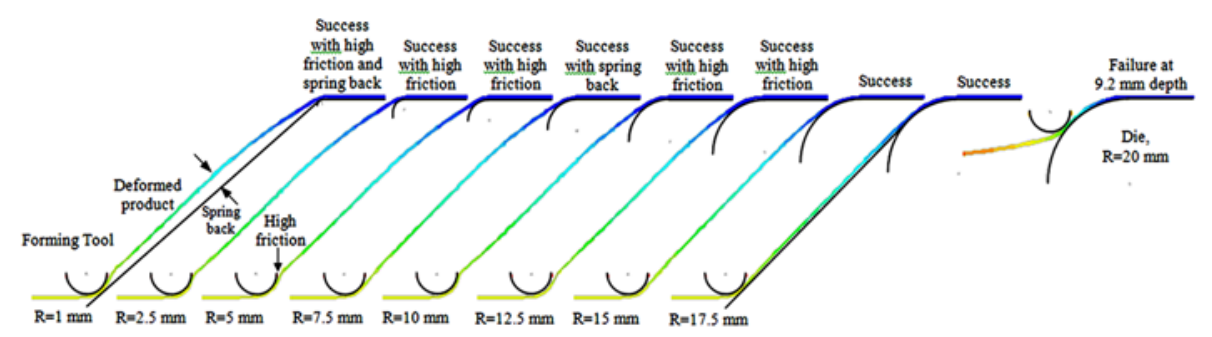

Fig. 4. SPIF process products, series b. 
Table 3. Series a, effect of supporting edge radius.

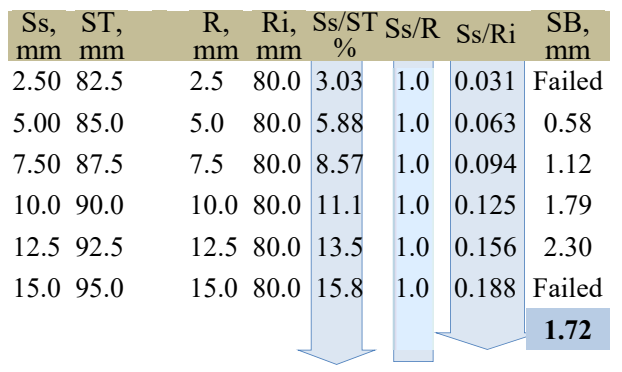

Table 4. Series b, effect of supporting edge radius.

\begin{tabular}{|ccccc|c|c|c|}
$\begin{array}{c}\mathrm{Ss}, \\
\mathrm{mm}\end{array}$ & $\begin{array}{c}\mathrm{ST}, \\
\mathrm{mm}\end{array}$ & $\begin{array}{c}\mathrm{R}, \\
\mathrm{mm}\end{array}$ & $\begin{array}{c}\mathrm{Ri}, \\
\mathrm{mm}\end{array}$ & $\begin{array}{c}\mathrm{Ss} / \mathrm{ST} \\
\%\end{array}$ & $\mathrm{Ss} / \mathrm{R}$ & $\mathrm{Ss} / \mathrm{Ri}$ & $\begin{array}{c}\mathrm{SB} \\
\mathrm{mm}\end{array}$ \\
\hline 10.0 & 90.0 & 1.0 & 89.0 & 11.11 & 10.0 & 0.112 & 2.80 \\
10.0 & 90.0 & 2.5 & 87.5 & 11.11 & 4.00 & 0.114 & 2.74 \\
10.0 & 90.0 & 5.0 & 85.0 & 11.11 & 2.00 & 0.118 & 2.31 \\
10.0 & 90.0 & 7.5 & 82.5 & 11.11 & 1.34 & 0.121 & 2.12 \\
10.0 & 90.0 & 10.0 & 80.0 & 11.11 & 1.00 & 0.125 & 1.73 \\
10.0 & 90.0 & 12.0 & 77.5 & 11.11 & 0.80 & 0.129 & 1.30 \\
10.0 & 90.0 & 15.0 & 75.0 & 11.11 & 0.67 & 0.133 & 1.14 \\
10.0 & 90.0 & 17.0 & 72.5 & 11.11 & 0.57 & 0.138 & 0.51 \\
10.0 & 90.0 & 20.0 & 70.0 & 11.11 & 0.50 & 0.143 & Failed \\
\hline
\end{tabular}

Springback is defined as a maximum deviation value in deformed blank comparing with the designed profile by CAD system of product. The prediction of the simulation models demonstrates increasing values of springback in series a, where the values of the supporting plate radius is increased, (Table 3 and Figure 3 ). The models failed with the values $\mathbf{R}=\mathbf{2 . 5}$ $\mathbf{m m}$ and $\mathbf{R}=15 \mathrm{~mm}$, due to the gap between the forming tool and the supporting edge less than the blank thickness used and increased the springback until accumulating the deformed blank around the forming tool. Also, the springback value increases from 0.58 to $2.3 \mathrm{~mm}$ with $\mathrm{R}=5$ to $\mathrm{R}=12.5 \mathrm{~mm}$ support plate radius, as shown in Figure 5 (series a). Springback appears to be directly proportional with increasing the support plate radius at constant internal radius of the supporting plate, $80 \mathrm{~mm}$. Inversely, the effect of decreasing the internal supporting radius caused reducing the springback clearly $(87.5$ to $70 \mathrm{~mm}$ from the blank center, to be 2.8 to $0.51 \mathrm{~mm}$, respectively), (series b) (Table 4 and Figure 4 and 6).

The results demonstrated that increasing the supporting plate edge radius, $\mathrm{R}$ from 2.5 to 15 $\mathrm{mm}$, and with a constant value condition of internal supporting plate radius, $\mathrm{Ri}=80.0$, springback increases, as shown in series an (74\% as shown in the Table 3); constant supporting plate space, $\mathrm{Ss}=10 \mathrm{~mm}(\mathrm{Ss} / \mathrm{ST}=11.11 \%)$, with increasing the value condition of supporting plate edge radius, from $\mathrm{R}=1$ to $17.5 \mathrm{~mm}$, and considering the edges of the blank, under the blank holder pressure shows clear improvement by reducing the springback $84 \%$, as shown in Table 4 .

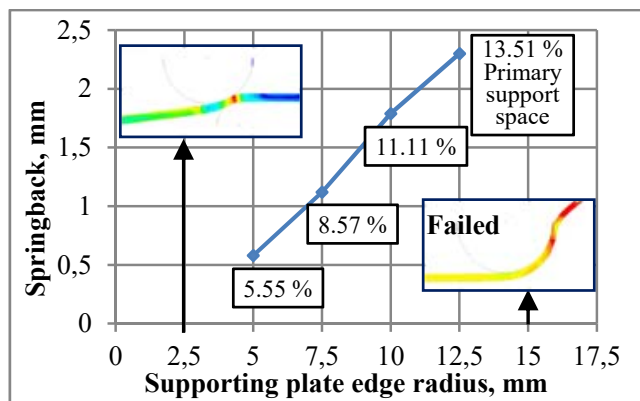

Fig. 5. Springback effect, Series a.

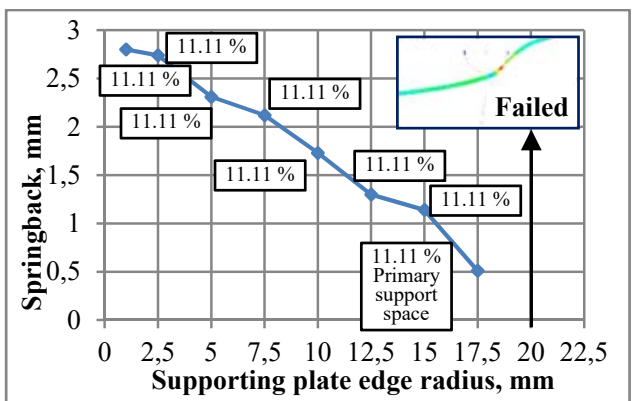

Fig. 6. Springback effect, Series b.

Increasing of the spacing ratio $\mathrm{Ss} / \mathrm{ST}$ and $\mathrm{Ss} / \mathrm{Ri}$, (where: ST, Total Space), for series a, results in increasing the spring back, even with different supporting edge radius and constant position. Also, the ratio $\mathrm{Ss} / \mathrm{R}=1$ is constant (Figure 3). Accumulation of the deformed blank around the forming tool acts when decreasing the internal support plate radius and increasing the supporting edge radius until $\mathrm{R}=20 \mathrm{~mm}$ during the deforming progress. As a result, the failure is predicted. The strain distributions range from $80-92.5 \mathrm{~mm}$ to $80-100 \mathrm{~mm}$ from 
product center because of increasing of $\mathrm{R}$, as shown in Figure 7. Decreasing the gap (toolsupporting edge) during tool movement caused strains of $\mathrm{R}=2.5$ and $\mathrm{R}=15$ to increase. The strains at local position of the tool are decreasing with increasing $\mathrm{R}$ and indirect contact with low levels. The strain behavior of series $\mathrm{d}$ can be divided into four regions from the product center (Figure 8). Decreasing the strain distributions at the regions between $35-45 \mathrm{~mm}$ and $85-95 \mathrm{~mm}$ represent an indication of reducing springback. The strain behavior is similar at the tool-blank contact region $(45-85 \mathrm{~mm})$, while the indirect contact region $(0-35 \mathrm{~mm})$ suffers low level increasing.

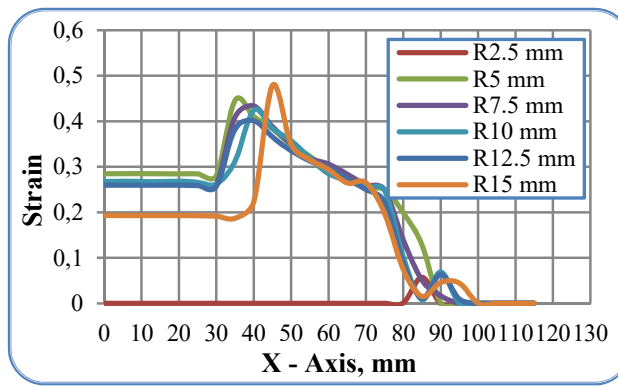

Fig. 7. Strain distributions, Series a.

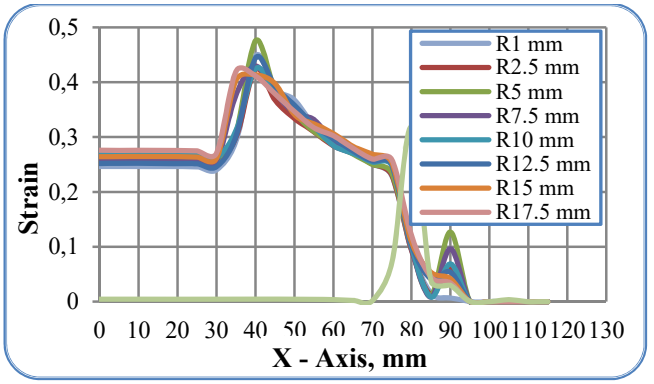

Fig. 8. Strain distributions, Series b.

\section{Conclusions}

The research is presenting the detail of the supporting edge radius effect and the internal supporting plate diameter influences with respect to adjustment in the incremental formability.

The results show that increasing the supporting plate radius with respect to the supporting space to total free blank ratio gives good results for reducing the springback effect.

Strain behavior of the supporting plate edge radius represents a good indication for improving the product profile; especially at the critical regions (supporting space caused springback). The supporting plate (edge radius and internal radius) is adjusting the deformation rate of the blank in depth.

\section{References}

1. Y. Luo, K. He, R. Du, M. Hoque, ISBN: 978-953-307-970-7, InTech, pp. 365-392 (2011)

2. D. Nasulea, G. Oancea, MSE 2017, MATEC Web of Conf., 121, 03017 (2017)

3. J. Jeswiet, F. Micari, G. Hirt, A. Bramley, CIRP Annal Manuf. Technol. 54(2), 88 (2005)

4. A. N. Bramley, F. Vollersten, M. Kleiner, Verlag Meisenbach Bamberg, pp. 95-102 (2001)

5. J. R. Duflou, B. Lauwers, J. Verbert, Y. Tunckol, H. De Baerdemaeker, 8th ESAFORM Conf. on Mate. Form., 675 (2005)

6. V. Oleksik, A. Pascu, C. Deac, R. Fleacă, O. Bologa, Int J Mater. Form., 3(S1), 935 (2010)

7. G. Ambrogio, L. Filice, L. Fratini, F. Micari, Proc. of 6th Conf. ESAFORM., 175 (2003)

8. L. Junchao, P. Geng, J. Shen, Int. J.Adv. Manuf. Technol., 68(9-12), 2637 (2013)

9. G. Ambrogio, L. De Napoli, L. Filice, M. Muzzupappa, Proc. of 7th ASME ICSDA, 3, 339 (2004)

10. G. Hirt, J. Ames, M. Bambach, R. Kopp, Annals of CIRP, 53, 203 (2004)

11. B. Lu, J. Chen, H. Ou, J. Cao, J. Mater. Process. Technol., 213(7), 1221 (2013)

12. H. Meier, V. Smukala, O. Dewald, Proc. of 12th Int. Conf. on Sheet Metal, 344, 599 (2007)

13. J. R. Duflou, B. Callebaut, J. Verbert, CIRP Ann. Manuf. Techn., 56(1), 273 (2007)

14. J, R. Duflou, B. Callebaut, J. Verbert, Int. J. Mach. Tools Manuf., 48(5), 543 (2008)

15. K. I. Abass, 21 ${ }^{\text {st }}$ IManE\&E 2017 Conf., MATEC Web of Conf., 112, 02003 (2017) 